\title{
Comparative study of Shot creep of single-phase titanium alloys in air and neutral gas environment on the test temperature in range from 673 to $1323 \mathrm{~K}$
}

\author{
Sergey Smirnov, Lev Zamaraev \\ Institute of Engineering Science of the Ural Branch of the Russian Academy of Sciences, Ekaterinburg, Russia \\ svs@imach.uran.ru, bttp:/ /orcid.org/0000-0002-2083-5377 \\ Leva.zam@mail.ru, bttp://orcid.org/0000-0003-4617-0825
}

\begin{abstract}
The paper presents the results of comparative studies of shortterm creep in tensile tests of the VT1-0 commercially pure titanium (analogue Grade 2 according to ASTM A485) and the VT5-1 alloy (analogue Grade 6 according to ASTM B265) in air and argon. Tests by the Dorn's method were carried out in a gas-tight chamber under constant pressure. The specimens were heated by passing alternating current. Empirical coefficients are determined in power dependences of the creep rate and the conventional creep strength on test temperature in the range from 673 to $1323 \mathrm{~K}$ for argon and air environment and nominal stress ranging between 4.45 and $9.36 \mathrm{MPa}$. It is found that heating in argon environment, as compared to heating in air, decreases the rate of short-term creep and increases creep strength at identical nominal stresses in the entire range of test temperatures. Calculations demonstrate that the energy of the activation of short-term creep does not depend on test conditions. This indicates that the deformation mechanism is unchanged.
\end{abstract}

KEYWORDS. Titanium alloy; Creep; Environment effect; Activation energy.

\section{INTRODUCTION}

$\mathrm{T}$ itanium and its alloys are widely used for making structural components operating at elevated temperatures and possessing good anti-corrosion and heat-resistance properties, with low specific gravity; however, one of the factors limiting their use is the danger of the development of the creep process. The phenomenon of metal creep as a whole is fairly well studied. General analytical dependences in the form of exponential, power and logarithmic laws were established, which describe the relation between creep strain rate (amount) at constant values of temperature and the value of applied stress [1-3]. A number of mechanical theories were proposed for the conditions of complex changes in the stress state and temperature [4-8]. 
Creep micromechanisms are continuing to be studied with the application of currently available metal physics methods [9-15], which are aimed at the specification of the general regularities in the effect of the previously established composition, structure, temperature-rate and loading conditions [16-18].

In the operation of structures and mechanisms metal creep is an undesirable phenomenon, which may reduce their service life, whereas in metal processing creep sometimes can be used to perform forming operations. Thus, experience in forming parts of a complex geometry under conditions of short-term high-temperature creep is reported in [19-22].

To design such processes, one is to know the behaviour of creep at temperatures higher than the conventional working range $(<850 \mathrm{~K}$ for titanium alloys), i. e. at temperatures when the rate of creep provides better manufacturability. Sometimes deformation under conditions of creep may be more competitive than that under conditions of superplasticity, when it is difficult to have optimal strain-rate conditions throughout the bulk of inhomogeneously deformed metal. Besides, the dislocation mechanism of deformation under creep does not cause any active growth of internal porosity, which is typical of superplasticity due to the micromechanisms of grain-boundary slip and metal grain recombination [23-27].

An important feature of titanium and its alloys is their ability to absorb gas actively as the heating temperature rises, namely, hydrogen at temperatures exceeding 323-343 K, oxygen at 673-773 K and nitrogen at 873-973 K. Therefore, in practice, protection from interaction with active gases contained in the air is required at temperatures starting from $673 \mathrm{~K}$. The largest number of studies deal with the creep of titanium alloys in the above-mentioned active media, which, as a rule, decrease creep rate [27-31] due to the formation of interstitial solid solutions with titanium and high-strength particles of oxides, hydrides and nitrides, which, when cooled, may substantially change the physical-mechanical properties of alloys [34-38].

Note that the dependence of the rate of short-term creep of titanium in hydrogen has a temperature range dependent on applied stress, where it increases abnormally [39] similarly to the well-known phenomenon of hydrogen plasticization [40].

The information on the effect of neutral gas environments on the creep of titanium and its alloys in the scientific and technical literature is scanty. Among the known studies, [41, 42] are worthy of notion, which report that the creep life of the $(\alpha+\beta)$ Ti- $6 \mathrm{Al}-4 \mathrm{~V}$ alloy in argon exceeds that in air due to the absence of oxidation of the specimen surface. The increase of crack propagation velocity in cyclic tests in air as compared to that in vacuum, which was found in [43], was also attributed to faster damage accumulation in an oxidising medium.

The aim of this paper is to study the effect of argon on the regularities in the short-term high-temperature creep of the VT1-0 commercially pure titanium and the VT5-1 alloy, which are single-phase $\alpha$-alloys, in comparison with studying creep in the air environment.

\section{EXPERIMENTAL}

$\mathrm{T}$ est specimens were made from 12-mm-diameter hot-pressed bars of the VT1-0 commercially pure titanium (analogue Grade 2 according to ASTM A485) and the VT5-1 alloy (analogue Grade 6 according to ASTM B265). The chemical composition of the VT1-0 is $0.028 \% \mathrm{Al}, 0.002 \% \mathrm{Si}, 0.036 \% \mathrm{Fe},-0.008 \% \mathrm{C}, 0.115 \% \mathrm{O}_{2}$, $0.003 \% \mathrm{H}_{2}, 0.012 \mathrm{Cr}+\mathrm{Mn}, 0.015 \% \mathrm{Cu}+\mathrm{Ni}$, the rest Ti. The VT5-1 alloy is as follows: $5.563 \% \mathrm{Al}, 0.145 \% \mathrm{Si}, 0.3 \% \mathrm{Fe}$, $0.09 \% \mathrm{C}, 0.18 \% \mathrm{O}_{2}, 0.012 \% \mathrm{H}_{2}, 0.28 \% \mathrm{Cr}, 0.045 \% \mathrm{Ni}$, the rest Ti. The temperature of the polymorphic $\alpha \rightarrow \beta$ transformation in the VT1-0 titanium under heating, when the lattice type changes from densely packed hexagonal to body-centred cubic, is $1160 \mathrm{~K}$ to $1170 \mathrm{~K}$. Similarly to commercially pure titanium, the VT5-1 alloy is single-phase, the polymorphic $\alpha \rightarrow \beta$ transformation in it occurs at a higher temperature, $1250 \mathrm{~K}$ to $1300 \mathrm{~K}$, and this being due to aluminium content in the alloy.

The gauge part of the test specimens was $50 \mathrm{~mm}$ long and $5 \mathrm{~mm}$ in diameter. To be fixed in the grips of the test facility, the specimens had 8-mm-diameter threaded bulges at the ends. Prior to testing all the specimens were annealed in a vacuum furnace at a temperature of $900 \mathrm{~K}$ for 1 hour. The grain structure of the alloys (see Fig. 1) was examined by electron backscatter diffraction (EBSD) on a VEGA II TESCAN raster electron microscope with an Oxford HKL 
Nordlys F+ EBSD analysis attachment. The average grain diameter of the VT1-0 and the VT5-1 alloy is $11.6 \mu \mathrm{m}$ and $2.8 \mu \mathrm{m}$ respectively.
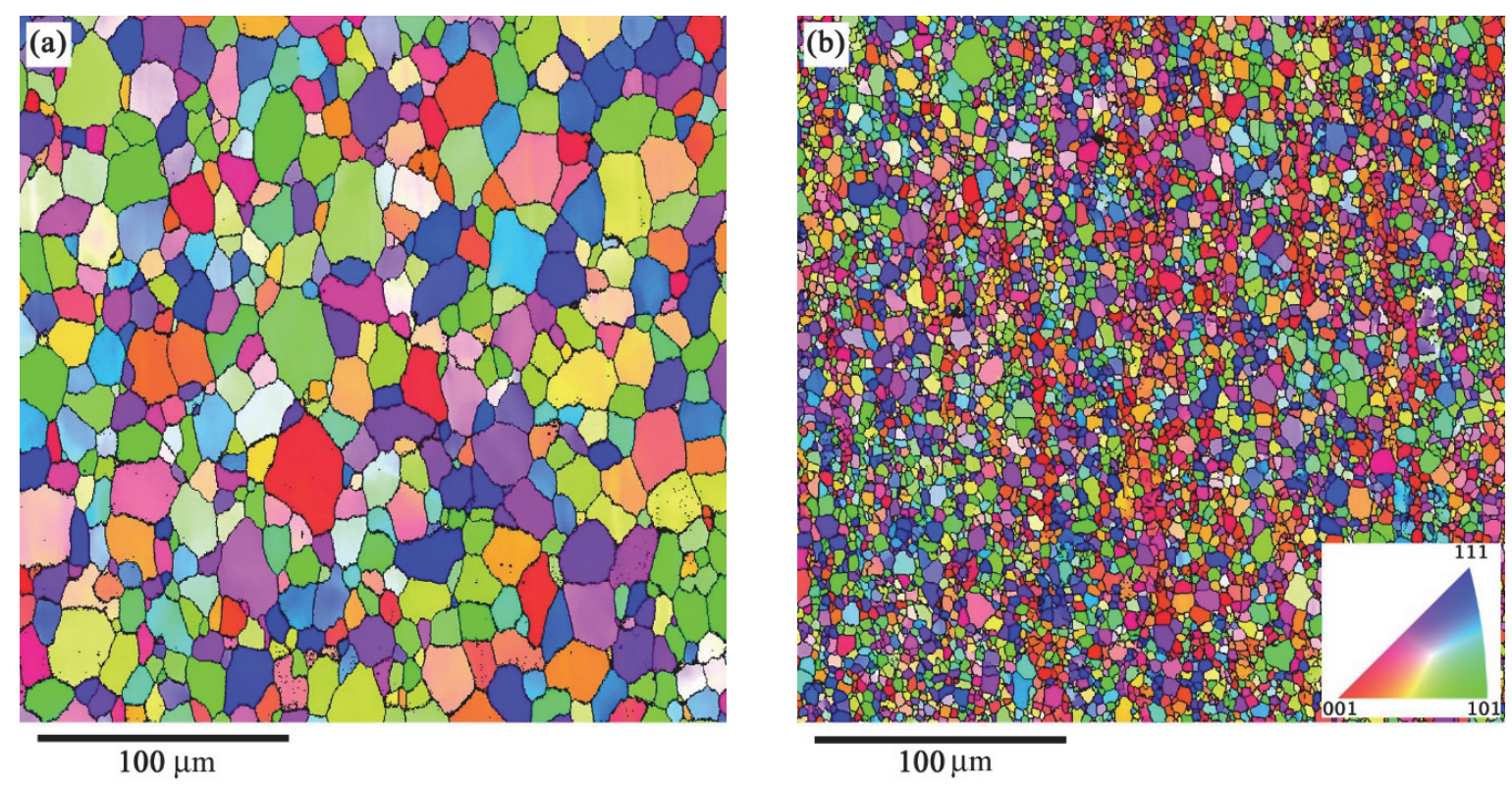

Figure 1: EBSD images of the microstructure of the VT1-0 (a) and the VT5-1 alloy (b).

The tests were performed on a specialised device (Fig. 2) enabling the elongation of the specimens to be continuously fixed during heating under the action of tensile stresses in different gas environments [44].

To perform the tests, specimen (1) was set in a specimen hang-up device (2) and covered with a cap forming a gas-tight chamber (3). The tensile force was produced by a set of lead weights (4). The specimen was heated by passing $50 \mathrm{~Hz}$ alternating current through a power transformer with automated amperage control to $750 \mathrm{~A}$. The heating temperature was controlled by a chromel-alumel thermocouple (6) welded to each specimen in the middle of its gauge part. The testing process was visually observed through quartz glass windows in the cap. The specimen elongation change was recorded by a resistive sensor (5). The sensor and the thermocouple were connected to a computer (8) through a signal transducer (7). The working chamber air was displaced by gaseous argon from a tank with an excessive pressure of $0.5 \mathrm{MPa}$, which was then kept constant during the test.

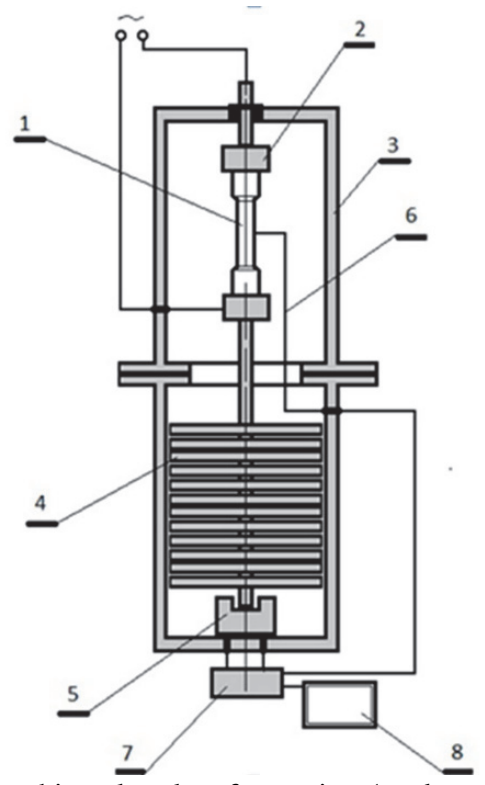

Figure 2: Scheme of the working chamber for testing (explanations in the text). 
J.E. Dorn's method reported in [45] was used to determine creep rate, according to which the temperature was changed stepwise during specimen heating, the tensile stress remaining unchanged. The temperature jump $\Delta T$ was $30 \mathrm{~K}$ and it was attained by a fixed change of amperage. The period of stepwise temperature rise was followed by a hold period. The total duration of each stage was $500 \mathrm{~s}$. When J.E. Dorn's method is applied, it is commonly supposed that, since the temperature jump is insignificant and the stress before and after temperature change remains unchanged, the change in the elastic modulus and the substructure can be neglected. In terms of this supposition, the creep rate change depends only on temperature variation. The specimens were tested at temperatures ranging from $673 \mathrm{~K}$ to $1323 \mathrm{~K}$ at nominal tensile stresses $\sigma=4.45,6.91$ and $9.36 \mathrm{MPa}$, which were below the yield stress of the alloys at maximum test temperatures (12 MPa for the VT1-0 and $45 \mathrm{MPa}$ for the VT5-1). Nominal stress was calculated as the ratio of tensile force to the initial specimen area.

The experimental results were averaged from three tests conducted under identical conditions. Figure 3 shows the variation in the readings of the elongation sensor (line 1) during VT5-1 specimen heating at $\sigma=9.36 \mathrm{MPa}$ as an example of initial experimental data. Each experiment with a loaded specimen was duplicated by an experiment in which the specimen was heated without suspended weights at the same time and temperature parameters (line 2). This enabled us to exclude the contribution of the value of temperature-induced strain and instrumentation elements to the recorded elongation. The difference in the measurements is attributed to specimen elongation under creep. The tests were performed only at the stage of the uniform elongation of the gauge part of the specimen, without reaching the stage of strain localisation and necking.

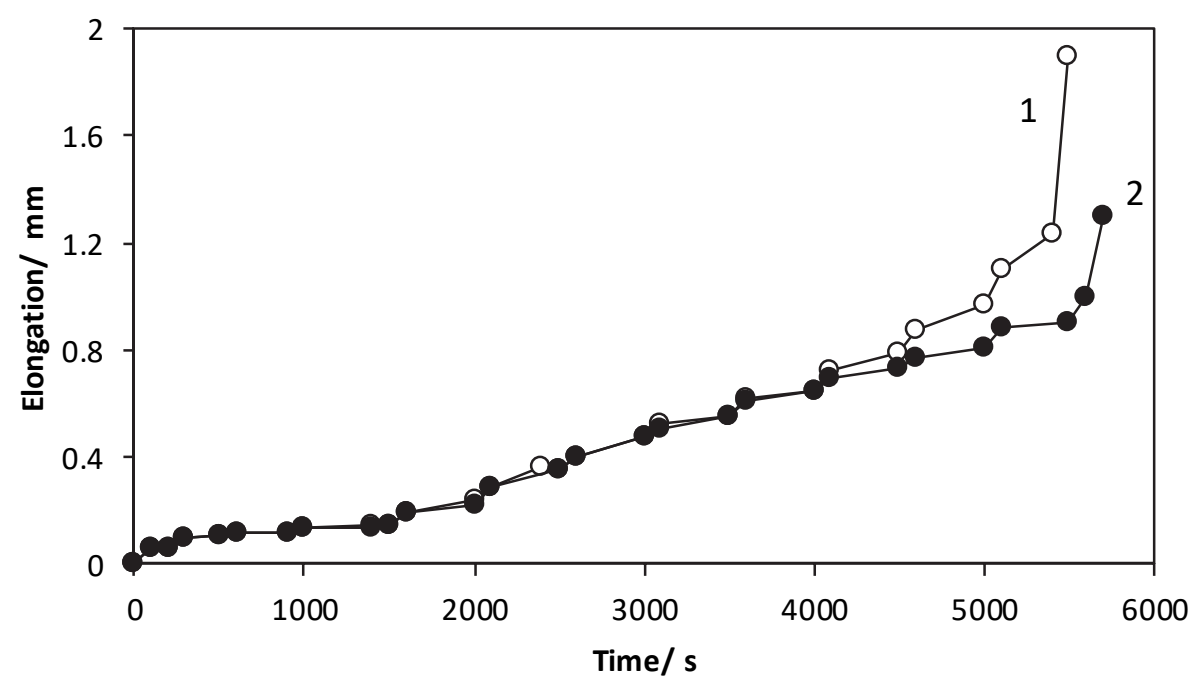

Figure 3: Diagrams of the VT5-1 alloy specimen elongation heated in argon at $\sigma=9.36 \mathrm{MPa}(1)$ and $\sigma=0(2)$

The scheme shown in Fig. 4 explains the procedure of experimental data processing at one of the heating steps. For the instance mentioned, at the 4000th second of heating (point A) amperage was increased, and this caused stepwise specimen heating from $1073 \mathrm{~K}$ to $1103 \mathrm{~K}$ (point B); thereafter, in the time interval $\Delta \tau=4100-4500 \mathrm{~s}$, a hold was made at a constant temperature of $1103 \mathrm{~K}$. A straight-line portion BC is highlighted on the diagram, on which creep-induced specific elongation $\Delta \varepsilon_{i}$ at the $i$-th stage of testing is calculated as

$$
\Delta \varepsilon_{i}=\frac{\Delta L_{i+1}-\Delta L_{i}}{L_{i}}
$$

where $\Delta L_{i+1}$ and $\Delta L_{i}$ are creep-induced specimen elongation at the end and beginning of holding at constant temperature $T_{i} ; L_{i}$ is specimen gauge length at the beginning of each hold period.

The average creep rate on the hold portion is calculated as

$$
v_{i}=\frac{\Delta \varepsilon_{i}}{\Delta \tau_{i}},[1 / \mathrm{s}]
$$


where $\Delta \tau_{\mathrm{i}}$ is soaking time at constant temperature (s); $\Delta \varepsilon_{\mathrm{i}}$ is creep-induced specific elongation at the $\mathrm{i}$-th step of temperature variation.

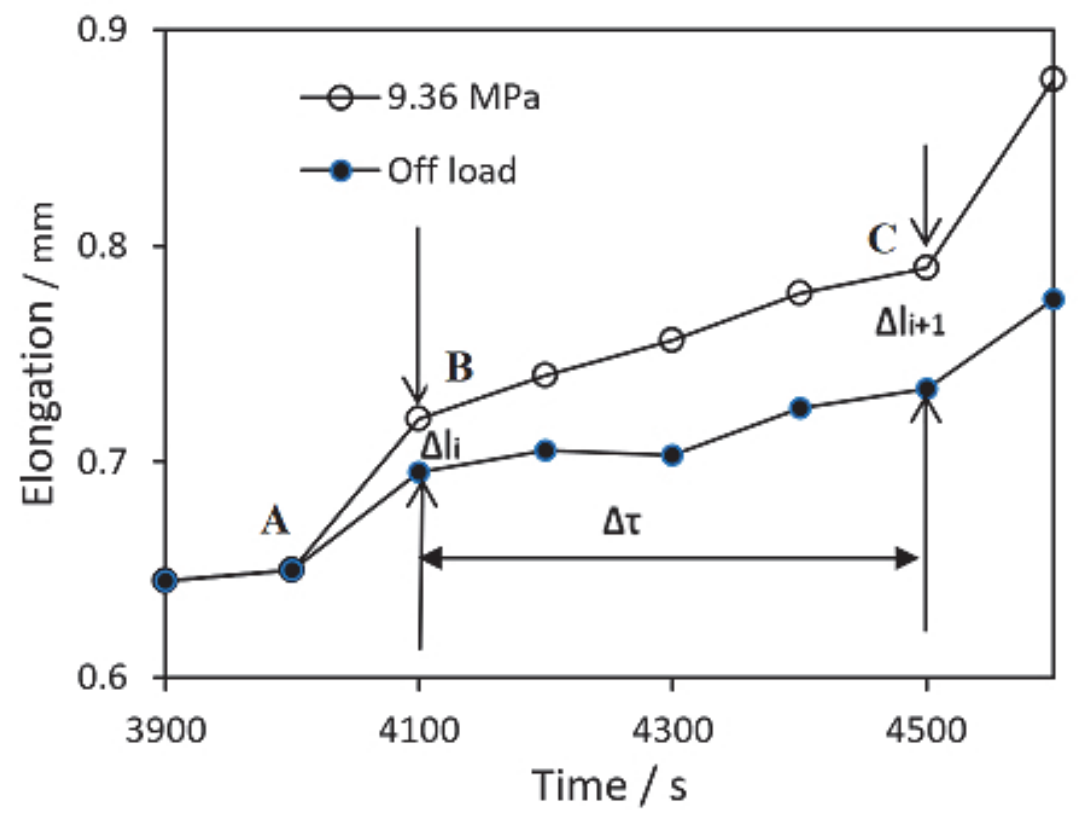

Figure 4: Procedure of experimental data processing

The steady-state creep activation energy $\Delta H_{i}$ at the $i$-th step of heating is calculated by the formula found in [45],

$$
\Delta H=\frac{R \ln \left(\frac{v_{i}}{v_{i+1}}\right)}{\Delta \tau_{i}},[\mathrm{~kJ} / \mathrm{mol}],
$$

where $R=8.314459810^{-3}[\mathrm{~kJ} /(\mathrm{mol} \cdot \mathrm{K})]$ is the universal gas constant.

The results of calculations by Eq. (3) is averaged for each material and environment tested. In order to determine conventional creep strength $\sigma_{0.2 / 1}^{T}$, the heating temperature $T$ at which 1 hour soaking was accompanied by permanent elongation of $0.2 \%$ at specified nominal tensile stress $\sigma$ was recorded.

\section{RESULTS}

he experimental results on the determination of creep rate at the steady-state stage are demonstrated in Figs. 5 and 6. To describe them analytically, we use the well-known exponential dependence found in [45]

$$
v=A \sigma^{n} \exp \left(-\frac{\Delta H}{R T}\right),[1 / \mathrm{s}]
$$

where $A$ and $n$ are empirical coefficients. 

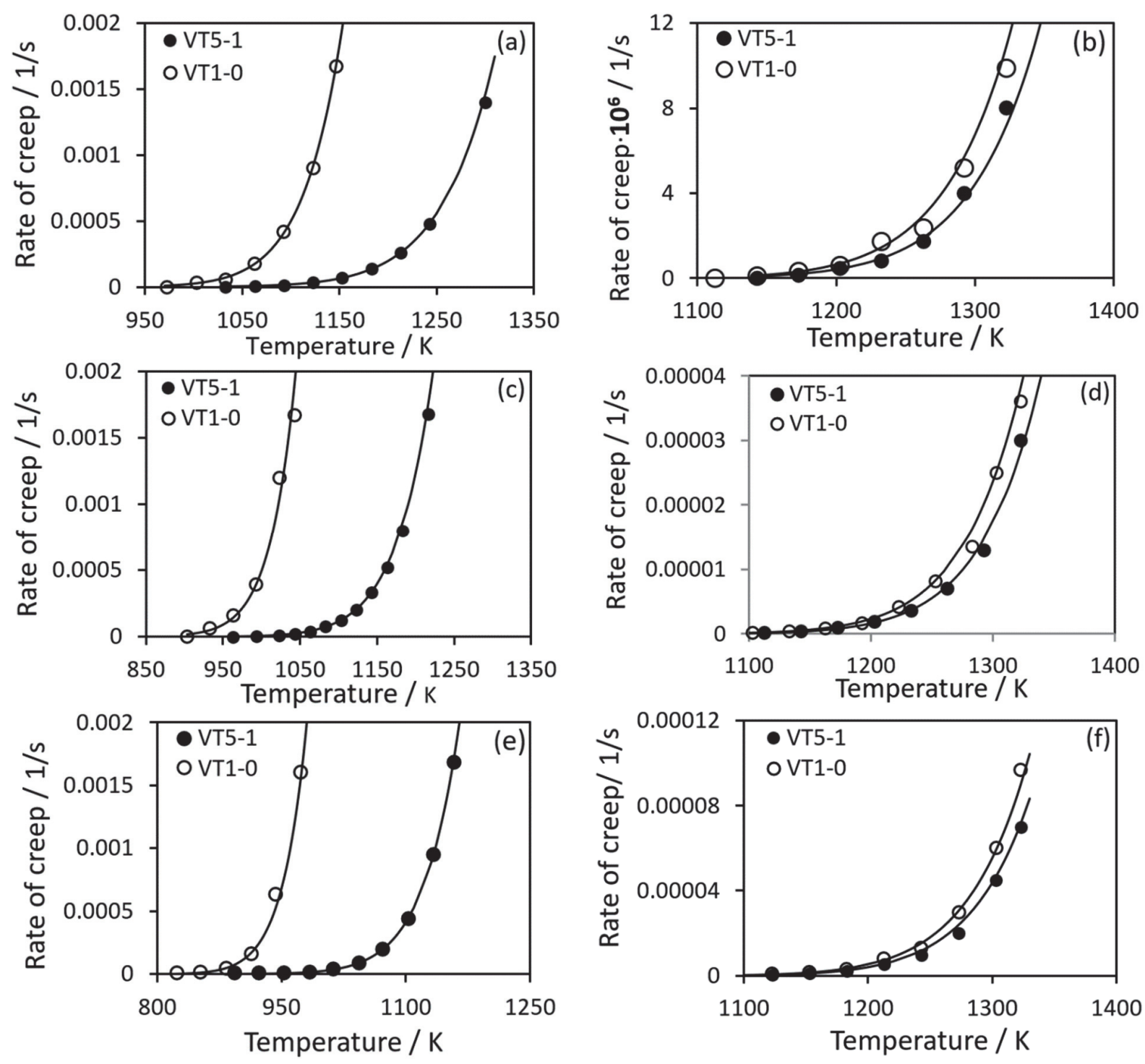

Figure 5: The rate of steady-state creep as dependent on heating temperature at tensile stress $\sigma=6.91 \mathrm{MPa}$ (The dots on the graphs denote averaged experimental data and the lines represent the results of approximation by approximating dependences).

The rate of steady-state creep as dependent on heating temperature at tensile stress. a,b - $\sigma=4.45 ; \mathrm{c}, \mathrm{d}-6.91$ : e,f - 9,36 MPa. a,c,e - in the air environment. b,d,f - in the argon environment (The dots on the graphs denote averaged experimental data and the lines represent the results of approximation by approximating dependences).

To determine the empirical coefficients $A$ and $n$, we use the data obtained from testing at nominal stresses $\sigma=4.45$ and $9.36 \mathrm{MPa}$. For higher accuracy, they are determined by the linearized dependence

$$
\ln v=\ln A+n \ln \sigma-\frac{\Delta H}{R T}
$$

The values of the empirical coefficients, the averaged activation energy values and the temperature ranges in which they were obtained are shown in Table 1.

The adequacy of the obtained approximation is estimated by comparing the results calculated by Eq. (4) using the found values of $A$ and $n$ with the data obtained from the experimental results at the nominal stress $\sigma=6.91 \mathrm{MPa}$. The calculations involve the use of the averaged activation energy values $\Delta \mathrm{H}_{a v}$ given in Table 1. As a result, it has been discovered that the found approximation coefficients offer an accurate description of the 
experimental data with the approximation reliability coefficient $\mathrm{R}^{2}>0.96$ in the studied temperature ranges. Figure 5 shows the test temperature dependences of the creep rates of the materials, which have been obtained from calculating by Eq. (4), and the data obtained from experimental data processing.

\begin{tabular}{cccccc}
\hline & Environment & $\Delta \mathrm{H}, \mathrm{kJ} / \mathrm{mol}$ & $A 10^{-4}$ & $n$ & Temperature range, $\mathrm{K}$ \\
\multirow{2}{*}{ VT1-0 } & air & 273 & 18.7 & 6.77 & $900-1100$ \\
& argon & 302 & 13.5 & 2.83 & $1050-1350$ \\
VT5-1 & air & 260 & 8.06 & 4.17 & $950-1200$ \\
& argon & 307 & 9.48 & 3.09 & $1100-1350$ \\
\hline
\end{tabular}

Table 1: The values of activation energy and the empirical coefficients in Eq. (4)

The statistical processing of the experimental results on the determination of the conventional short-term creep strength $\sigma_{0.2 / 1}$ has revealed that the values of the heating temperature $T_{0.2 / 1}$ at which the nominal stresses cause permanent creep strain of $0.2 \%$ within a 1 -hour hold are related to the values of $\sigma_{0.2 / 1}$ through the polynomial dependence (the approximation reliability coefficient $\mathrm{R}^{2}>0.98$ )

$$
T_{0.2 / 1}=c_{1} \sigma_{0,2 / 1}^{2}+c_{2} \sigma_{0.2 / 1}+c_{3},
$$

where $c_{1}, c_{2}$ and $c_{3}$ are the approximation coefficients given in Table 2 .

\begin{tabular}{cccccc}
\hline & Environment & $c_{1}$ & $c_{2}$ & $c_{3}$ & Temperature range, K \\
\multirow{2}{*}{ VT1-0 } & air & -1.25 & -13.09 & 1054.6 & $800-1050$ \\
& argon & -0.96 & -14.81 & 1194.5 & $950-1200$ \\
\multirow{2}{*}{ VT5-1 } & air & -0.835 & -16.59 & 1120.4 & $850-1100$ \\
& argon & -0.54 & -20.74 & 1244.2 & $1000-1200$ \\
\hline
\end{tabular}

Table 2: The values of the empirical coefficients in Eq. (6)

The coefficients $c_{1}$ and $c_{2}$ are physically meaningless, and the coefficient $c_{3}$ can be treated as the temperature at which creep develops unaffected by external stresses. The experimental data on the determination conventional short-term creep strength $\sigma_{0.2 / 1}$ and the results of calculations by Eq. (6) are given in Fig. 6.

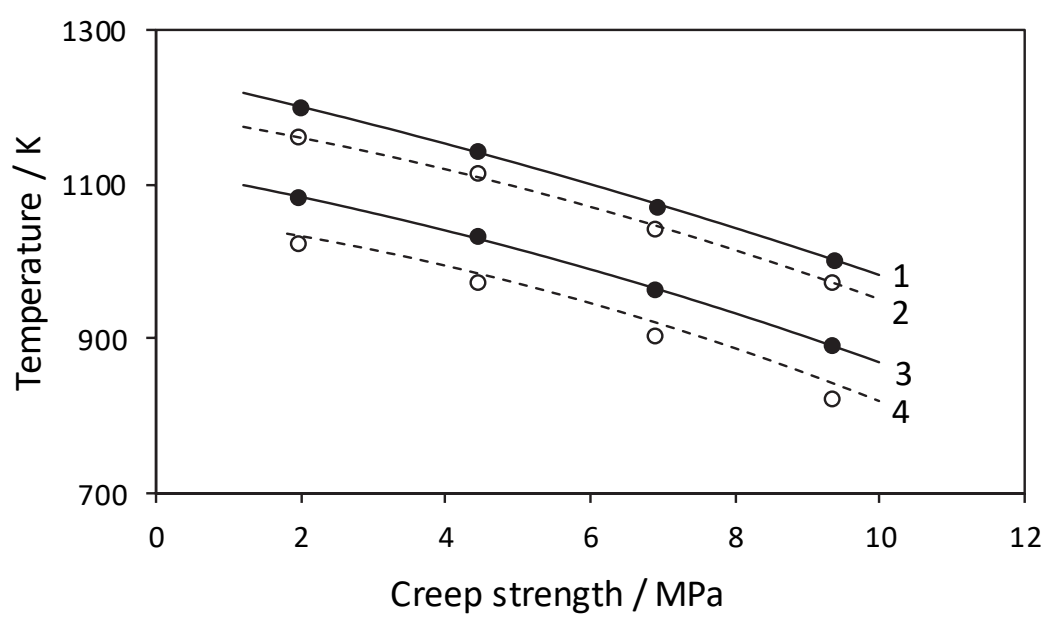

Figure 6: Conventional short-term creep strength as dependent on heating temperature (1.Ti-5Al - in the argon environment; 2. Grade 2. - in the argon environment; 3. Ti-5Al - in the air environment; 4. Grade 2 - in the air environment). 


\section{DISCUSSION}

$\mathrm{T}$ he obtained results demonstrate that the composition of the gas medium as the test environment essentially affects the creep characteristics. When the specimens made of both alloys are heated in the argon environment, the creep rate $v$ significantly decreases and the conventional creep strength $\sigma_{0.2 / 1}$ increases as compared to similar heating in the air environment. With a qualitative similarity of the mentioned behaviour, in the VT5-1 alloy creep is noted at higher temperatures than in the VT1-0 commercially pure titanium and has a lower rate, this being due to the presence of a solid aluminium solution in titanium.

The identification of the creep mechanism in the VT1-0 commercially pure titanium under conditions of the tests is made by the deformation mechanism maps found in [18]. To do this, the values of the complex $\sigma_{S} / \mu($ $\sigma_{S}=\sigma / \sqrt{3}$ is shear stress, $\mu$ is the shear modulus) and the values of homologous temperature $T / T_{m}$ corresponding to the conditions of the experiments ( $T_{\mathrm{m}}=1957 \mathrm{~K}$ is melting temperature) are calculated. The value of $\mu$ at the test temperature is determined by the formula from [18]

$$
\mu=\mu_{0}\left[1+k_{T} \frac{(T-300)}{T_{m}}\right],
$$

where $\mu_{0}=4.36 \cdot 10^{4} \mathrm{MN} / \mathrm{m}^{2}$ is the shear modulus at $T=300 \mathrm{~K}, k_{\mathrm{T}}=-1.2$ is the temperature dependence coefficient of the modulus $\mu$ [46].

Thus, with the application of a deformation mechanism map for commercially pure titanium, we have established that, according to the classification proposed by H.J. Frost and M.F. Ashby in [18], the conditions of the tests correspond to the high-temperature creep region controlled by the bulk diffusion of dislocation climb, where the power dependence of strain rate on applied stress is true. Also note that the found values of the Dorn constant $A$ and activation energy $\Delta H$ (see Table 1) are close to the results reported in [17,18], which were obtained on specimens made of purer titanium (99.98\%), with $A=7.7 \cdot 10^{4}$ and $\Delta H=242 \mathrm{~kJ} / \mathrm{mol}$.

The calculated values of activation energy $\Delta H$ range between $260 \mathrm{~kJ} / \mathrm{mol}$ and $307 \mathrm{~kJ} / \mathrm{mol}$ for the both materials in air and argon, i. e. they are much higher than the values of $\Delta H$ from [18] for the mechanisms of bulk diffusion $(\Delta H=150 \mathrm{~kJ} / \mathrm{mol})$ and diffusion on grain boundaries and dislocation tubes $(\Delta H=97 \mathrm{~kJ} / \mathrm{mol})$. That is, testing in argon does not change the deformation mechanism from testing in the air environment, although the creep rate decreases significantly. The latter can be explained from the general ideas of the governing effect of the surface condition on the processes of deformation of metal materials. In the case under study the creep rate decrease in argon may be due to the absence of oxidation on the specimen surface, which, according to [7, 43], intensifies the evolution of creep in titanium alloys.

The established facts of lower creep rate and higher conventional creep strength for short-term hightemperature creep in argon may be of a certain practical interest. It is not uncommon when, in the operation of various devices and structures, emergencies may occur which are caused by a rapid temperature rise in processes or by a thermal action in a fire. There appears a probability of a local or total loss of structural strength upon the attainment of conditions for the occurrence of short-term creep causing the deformation of structural components or even their complete failure. The use of a protective inert medium can decrease the risks of disastrous consequences of emergency situations of the kind.

\section{CONCLUSIONS}

$\mathrm{F}$ rom the results of comparative experimental research on short-term high-temperature creep of the VT10 commercially pure titanium and the VT5-1alloy in air and in argon, we have found that 
- heating in argon, if compared with heating in air, decreases creep rate and increases conventional creep strength, nominal stresses being the same in the whole test temperature range;

- the short-term creep activation energy for the materials studied in air and argon, determined by the Dorn method, has close values of 250 to $300 \mathrm{~kJ} / \mathrm{mol}$ at temperatures ranging from $900 \mathrm{~K}$ to $1350 \mathrm{~K}$.

- Besides, we have determined:

- empirical coefficients in the dependence relating creep rate to temperature, nominal stress and creep activation energy;

- empirical coefficients in the test temperature dependence of conventional creep strength.

\section{ACKNOWLEDGEMENTS}

his work was supported by the Russian Academy of Sciences under project number AAAA-A18118020790142-9 (theme No. 0391-2016-0004).

\section{REFERENCES}

[1] McLean, D., (1962) Mechanical Properties of Metal, New York, Wiley.

[2] Dorn, J.E., Conrad, H., Robertson, W.D., (1957) Creep of single crystals and polycrystals of aluminum, lead, and tin, Trans. AIME.

[3] Garofalo, F., (1963) An empirical relation defining stress dependence of minimum creep rate in metals, Trans. Metall. Soc/ AIME, 227, pp. 351-356.

[4] Kachanov, L.M., (1972). Fracture Under Conditions of Creep at Complex Loading, Izv Akad Nauk. S.S.S.R., Mekh. Tverd. Tela, 5, pp.11., in Russian.

[5] Kachanov, L.M., (1999). Rupture time under creep conditions, Int. J. Fract., 97(1-4), pp. 11-18.

[6] Lemaitre, J., (1985). A continuous damage mechanics model for ductile fracture, ASME J. Eng. Mater. Technol., $107(1)$, pp. 83-89.

[7] Goswami, T., (1995). Creep-Fatigue Life Prediction — A Ductility Model, High Temp. Mater. Processes, 14(2), pp. 101-114.

[8] Brnic, J., Niu, Ji-tai, Turkalj, G., Canadija, M., Lanc, D., (2010). Experimental determination of mechanical properties and short-time creep of AISI 304 stainless steel at elevated temperatures, International Journal of Minerals, Metallurgy and Materials, 17(1), pp. 39-45. Doi.org/10.1007/s12613-010-0107-0.

[9] Yu, H., Dong, C., Jiao, Z., Kong, F., Chen, Y., Su, Y., (2013). High temperature creep and fatigue behavior and life prediction method of a TiAl alloy, Acta Metallurgica Sinica, 49(11), pp. 1311-1317. DOI: 10.3724/SP.J.1037.2013.00434.

[10] Dastidar, G., Khademi, V., Bieler, T.R., Pilchak, A.L., Crimp, M.A., Boehlert, C.J., (2015). The tensile and tensilecreep deformation behavior of Ti-8Al-1Mo-1V(wt\%), Mater. Sci. Eng. A, 636, pp. 289-300. DOI: 10.1016/j.msea.2015.03.59

[11] Li, H., Mason, D.E., Yang, Y., Bieler, T.R., Crimp, M.A., Boehlert, C.J. (2013). Comparison of the deformation behavior of commercially pure titanium and Ti-5Al-2.5Sn(wt.\%) at 296 and 728 K, Philos. Mag,. 93(21), pp. 28752895. DOI: $10.1080 / 14786435.2013 .791752$

[12] Badea, L., Surand, M., Ruau, J. Viguier, B., (2014), Creep behavior of Ti-6Al-4V from $450{ }^{\circ} \mathrm{C}$ to $600{ }^{\circ} \mathrm{C}$, UPB Scientific Bulletin, Ser. B: Chemistry and Materials Science, 76(1), pp. 185-196.

[13] Zong, Y., Liu, P., Guo, B., Shan, D., (2015). Investigation on high temperature short-term creep and stress relaxation of titanium alloy, Mater. Sci. Eng. A, 620, pp. 172-180. DOI: 10.1016/j.msea.2018.11.151.

[14] Gu, Y., Zeng, F., Qi, Y., Xia, C. Xiong, X. (2013). Tensile creep behavior of heat-treated TC11 titanium alloy at 450$550^{\circ} \mathrm{C}$, Mater. Sci. Eng. A, 575, pp. 74-85.

[15] Sahay, S.K., Singh, S.K., Goswami, B. and Ray, A.K. (2005). Creep behavior in Ti-based alloys, High Temp. Mater. Processes, 24(5), pp. 323-336. DOI: 10.1515/HTMP.2005.24.5.323.

[16] Honeycombe R.W.K., (1984). The plastic deformation of metals. Edward Arnold (Publ.) ltd., 2nd ed., 
[17] Doner, M., and Conrad, H., (1973). Deformation Mechanisms in Commercial Ti-50A (0.5 at. pct Oeq at Intermediate and High Temperatures (0.3-0.6 T $\mathrm{m}$ ), Metall. Mater. Trans. A, 4(12), pp. 2809-2817. DOI: 10.1007/BF02644581.

[18] Frost, H.J., Ashby, M.F, (1982). Deformation-mechanism maps: the plasticity and creep of metals and ceramics, Oxford, New York, Sydney, Pergamon Press, pp.166.

[19] Xiao, J.J., Li, D.S, Li ,X.Q., Ding, P., Zhao, K., Huang, X.Z, Xu, M.J. (2015). Process parameters optimization of Ti6Al-4V alloy sheet during hot stretch-creep forming, Transactions of Nonferrous Metals Society of China, 25(2), pp. 420-428. DOI: 10.1016/S1003-6326(15)63619-6.

[20] Xiao, J., Li D., Li, X., Jin C., Deng T., (2013). State of the art of hot stretch-creep compound forming for thin-wall titanium alloy components, Rare Metal Materials and Engineering, 42(12), pp. 2629-2635.

[21] Tongsheng, D., Dongsheng, L., Xiaoqiang, L., Pan, D., Kai, Z., (2014). Hot stretch bending and creep forming of titanium alloy profile, Procedia Engineering, 81, p 1792-1798. DOI: 10.1016/j.proeng.2014.10.234.

[22] Odenberger, E.L., Hertzman, J., Thilderkvist, P., Merklein, M., Kuppert, A., Stöhr, T., Lechler, J., Oldenburg, M., (2013). Thermo-mechanical sheet metal forming of aero engine components in Ti-6Al-4V, Part 1. International Journal of Material Forming, 6(3), pp. 391-402.

[23] Geckinli, A., (1983). Grain boundary sliding model for superplastic deformation, Met. Sci., 17(1), p 12-18.

[24] Arieli, A., Rosen, A., (1977). Superplastic deformation of Ti-6Al-4V alloy, Metall. Mater. Trans. A, 8(10), pp. 15911596.

[25] Ashby, M., Verrall, R., (1973). Diffusion-accommodated flow and superplasticity, Acta Metall., 21(2), pp. 149-163.

[26] Spingarn, J., Ni,x W., (1978) Diffusional creep and diffusionally accommodated grain rearrangement, Acta Metall., 26(9), pp. 1389-1398. DOI: 10.1016/0001-6160(78)90154-2.

[27] Alabort, E., Kontis, P., Barba, D., Dragnevski, K., Reed, R.C., (2016). On the mechanisms of superplasticity in Ti6Al-4V, Acta Mater., 105, pp. 449-463.

[28] B.A., Kolachev, Hydrogen in metals and alloys, Met. Sci. Heat Treat., 1999, 41(3), pp. 93-100. DOI: $10.1007 /$ BF02467692.

[29] Reis, D.A.P., Silva, C.R.M., Nono, M.C.A., Barboza, M.J.R., Piorino Neto, F., Perez, E.A.C., (2005) Effect of environment on the creep behavior of the Ti-6Al-4V alloy, Mater. Sci. Eng. A, 399(1-2), pp. 276-280.

[30] Rosen A., Rottem A., (1976). The effect of high temperature exposure on the creep resistance of Ti6Al4V alloy, Mater. Sci. Eng. A, 22, pp. 23-29.

[31] Lokoshchenko, A.M., Il'In, A.A., Mamonov, A.M., Nazarov, V.V., (2008). Analysis of the creep and long-term strength of VT6 titanium alloy with preliminarily injected hydrogen, Materials Science, 44(5), pp. $700-707$. DOI: $10.1007 /$ s11003-009-9128-0

[32] Grabovetskaya, G.P., Zabudchenko, O.V., Stepanova, E.N., (2010). Effect of hydrogen on the low-temperature creep of a submicrocrystalline Ti-6Al-4V alloy, Russian Metallurgy (Metally), 3(3), pp. 229-234. DOI: $10.1134 /$ S0036029510030134.

[33] Brandes, M.C., Baughman, M., Mills, M.J., Williams, J.C., (2012). The effect of oxygen and stress state on the yield behavior of commercially pure titanium, Mater. Sci. Eng. A, 551, pp. 13-18. doi.org/10.1016/j.msea.2012.04.058

[34] Paton, N.E., Williams, J.C., (1974). Hydrogen in Metals, Edited by I. M. Bernstein and A. W. Thompson, Metals Park, $\mathrm{OH}, \mathrm{ASM}, \mathrm{pp} .409$.

[35] Wasz, M.L., Brotzen, F.R., McLellan, R.B.,. Griffin, A.J, (1996). Effect of oxygen and hydrogen on mechanical properties of commercial purity titanium, Int. Mater. Rev., 41(1), pp. 1-12.

[36] Beevers, C.J., Warren, M.R., Edmonds, D.V., (1968). Fracture of titanium-hydrogen alloys, Journal of the Less Common Metals, 14(4), pp. 387-396. DOI: 10.1016/0001-6160(57)90169-4.

[37] Makarov, A.V., Gorkunov, E.S., and Kogan, L.Kh., (2007). Application of the eddy-current method for estimating the wear resistance of hydrogen-alloyed beta-titanium alloy BT35, Russian Journal of Nondestructive Testing, 43(1), pp. 21-26. DOI: 10.1134/S1061830907010032.

[38] Suzuki, H., Fukushima, H., Takai, K., (2015) Role of hydrides and solute hydrogen in embrittlement of pure titanium, Journal of the Japan Institute of Metals, 79(3), pp. 82-88. DOI: 10.2320/jinstmet.JC201402.

[39] Smirnov, S.V., Zamaraev, L.M., Matafonov, P.P., (2010). Role of hydrides and solute hydrogen in embrittlement of pure titanium, Russian Metallurgy (Metally), (1), pp. 67-70. DOI: 10.1134/S0036029510030134.

[40] Aksenov, Yu. A., Bashkin, I.O., Kolmogorov, V.L., Ponyatovskiy, Ye.G, Taluts, G.G., Kataya, V.K., Levin, I.V., Potapenko, Yu.I, Trubin, A.N., (1989). Influence of hydrogen on the plasticity and elastic stiffness of technical titanium VT1-0 at temperatures up to $750^{\circ} \mathrm{C}$. Physics of Metals and Metallography, 67 (5), pp.157.

[41] Reis, D.A.P., Moura Neto, C. De, Neto, F.P., Barboza, M.J.R., Da Silva, C.R.M., (2007). The oxidation effect in the titanium alloy at high temperature, SAE Technical Papers,. Code 90250. DOI: 10.4271/2007-01-2814. 
[42] Reis, D.A.P., Neto, C.M., Nono, M.D.C.A., Barboza, M.J.R., Da Silva, C.R.M., Neto, F.P. (2010). Development of a system to creep tests in controlled atmosphere. Proceedings of the 65th ABM International Congress, 18th IFHTSE Congress and 1st TMS/ABM International Materials Congress, 5, pp.4229.

[43] Evans W.J., Jones J.P., Williams S., (2005). The interactions between fatigue, creep and environmental damage in Ti 6246 and Udimet 720Li, Int. Journal of Fatigue, 27(10-12), pp. 1473-1484. DOI: 10.1016/j.ijfatigue.2005.06.029.

[44] Smirnov, S.V., Zamaraev, L.M., Zamyatin, A.N., Matafonov, P.P., (2012). Short-term thermal cyclic creep and fracture of a VT1-0 titanium alloy in a hydrogen atmosphere, Russian Metallurgy (Metally), (3), pp. 255-257. DOI: $10.1063 / 1.5017417$

[45] Sherby, O.D., Lytton, J.L., Dorn, J.E., (1957). Activation energies for creep of high-purity aluminum, Acta Metall., 5(4), pp. 219-227. DOI: 10.1016/0001-6160(57)90169-4.

[46] Sanchez, J.N. and de Fontaine, D. (1978). Anomalous diffusion in omega forming systems. Acta Metall., 26(7), pp. 1083-1095. DOI: 10.1016/0001-6160(78)90136-0. 